\title{
COVID-19-related anxiety and concerns expressed by pregnant and postpartum women-a survey among obstetricians
}

\author{
Madhuri H. Nanjundaswamy ${ }^{1}$ - Lakshmi Shiva ${ }^{1}$ - Geetha Desai ${ }^{1}$ - Sundarnag Ganjekar ${ }^{1} \cdot$ Thomas Kishore $^{2}$. \\ Uma Ram $^{3} \cdot$ Veena Satyanarayana ${ }^{2} \cdot$ Harish Thippeswamy ${ }^{1} \cdot$ Prabha S. Chandra $^{1}$
}

Received: 2 June 2020 / Accepted: 18 August 2020 / Published online: 25 August 2020

(C) Springer-Verlag GmbH Austria, part of Springer Nature 2020

\begin{abstract}
This paper from India describes anxieties that pregnant and postpartum women reported to obstetricians during the COVID-19 pandemic. Of the 118 obstetricians who responded to an online survey, most had been contacted for concerns about hospital visits (72.65\%), methods of protection (60.17\%), the safety of the infant $(52.14 \%)$, anxieties related to social media messages (40.68\%) and contracting the infection (39.83\%). Obstetricians felt the need for resources such as videos, websites and counselling skills to handle COVID-related anxiety among perinatal women.
\end{abstract}

Keywords COVID19 $\cdot$ Anxiety $\cdot$ Pregnancy $\cdot$ Postpartum $\cdot$ Women $\cdot$ India $\cdot$ Perinatal

\section{Introduction}

Pandemics, including COVID-19, have been shown to have major effects on mental health resulting in anxiety, depression and high stress levels (Wang et al., 2020). Pregnant mothers are a vulnerable population and may have several concerns and anxieties about the impact of COVID-19 infection on pregnancy and the foetus (Schwartz and Graham, 2020). There have been conflicting results about morbidity and mortality in pregnant women related to COVID-19 infection, including the possibility of vertical transmission (Alzamora et al., 2020; Di Mascio et al., 2020). Infectious epidemics have been shown to cause anxiety in pregnant women about several aspects of childbirth including disrupted expectations related to prenatal and postnatal care (Brooks et al., 2020). Research

This article is part of the Topical Collection on Women's mental health during the Covid-19 pandemic

Edited by: Anita Riecher-Rössler

Prabha S. Chandra

prabhasch@gmail.com

1 Department of Psychiatry, National Institute of Mental Health and Neurosciences (NIMHANS), Hosur Road, Bengaluru 560029, India

2 Department of Clinical Psychology, National Institute of Mental Health and Neurosciences (NIMHANS), Bengaluru 560029, India

3 Consultant Obstetrician, Seethapathy Clinic \& Hospital, 128 Royapettah High Road, Chennai, India in this area is just emerging. Among 71 pregnant mothers in Ireland, $36(50.7 \%)$ reported excessive worrying about their health during the COVID-19 pandemic (Corbett et al., 2020).

Studies done during earlier pandemics of the severe acute respiratory syndrome (SARS) and Zika virus have highlighted the need to sensitise all health care professionals about perinatal mental health (Dos Santos Oliveira et al., 2016; Ng et al., 2004). Pregnant and postpartum women are likely to first discuss their anxieties about COVID-19 with their obstetricians who may hence need to be first responders for mental health support. This is challenging when face to face contact with women is going to be limited.

We conducted an online survey among obstetricians to understand the nature of concerns about COVID-19 that pregnant and postpartum women expressed to them. We also asked about methods they used to handle psychological distress and their need for resources.

\section{Materials and methods}

Based on available literature regarding common concerns and anxieties among pregnant women in previous and including COVID-19, domains were shortlisted and items representing each domain were generated. Consensus regarding the items was established among all authors and experts and the final survey had 32 items. Part 1 had details about obstetricians such as gender, years of experience and number of deliveries 
conducted during the pandemic. It also included trimester wise distribution of women who had contacted the obstetricians for COVID-19-related concerns and anxiety. The second part of the survey was divided into two sections.

1. The first had 12 items related to nature of concerns expressed, including symptoms, protection, testing for COVID-19, the effect of infection on pregnancy and foetus, antenatal visits, safe delivery, the safety of the infant, breastfeeding, social distancing, media messages and concerns related to work.

2. The second had 10 items on anxiety and psychological distress including anxiety about the infection, infection control procedures not being followed by family members, excessive reading and receiving social media messages, boredom, distress about missing work, missing out on rituals like baby showers and sleep problems. We also enquired how often family members and husbands contacted the obstetrician about the patient's anxiety and two questions were related to methods obstetricians had employed to allay anxiety in these women and what aids or skills they would need to help women better during this period.

Each question was scored by respondents on a Likert scale of 'Very often', 'Often', 'Occasionally' and 'Not at all'. Distribution of responses is presented as frequencies and percentages.

An online survey using the platform Survey Monkey (https://www.surveymonkey.com/) was created. The weblink was sent out to all members of an obstetrics society in South India using a purposive method of sampling. Participants were assured of complete anonymity. Online consent was sought. The survey reached approximately 300 obstetricians during the periods April 5, to May 5, 2020, and 118 responded (40\%). The study was approved by the institutional ethics committee of the National Institute of Mental Health and Neurosciences, Bangalore, India.

\section{Results}

Among the 118 obstetricians who responded, 106 (89.83\%) were women, with $102(87 \%)$ having more than 10 years of experience; 54 (45.76\%) had conducted deliveries for more than ten women during this pandemic. Nearly $40 \%$ reported having been contacted by more than ten women because of anxiety related to COVID-19 and $14.4 \%$ reported that pregnant women under their care had been tested for the virus.

Almost $44 \%$ of the obstetricians reported that more than half of the calls received for COVID anxiety were from women in their third trimester and lesser than $25 \%$ from women in the first and second trimester. Also, 23 (19.66\%) obstetricians responded that family members and husbands who also called to discuss anxieties related to COVID-19.
The most frequent concerns reported to obstetricians were related to hospital visits for antenatal check-ups and ultrasound scans, protecting themselves from infection, social media messages, infant health after delivery and breastfeeding (Table 1).

The most common anxieties and distress reported were related to worrying social media messages, fear about contracting the infection, social isolation, family members not following infection control and missing out on childbirth-related rituals (Table 2).

Obstetricians mentioned using the following methods to handle COVID-19-related anxiety among pregnant and postpartum women-104 $(88.89 \%)$ provided reassurance, 94 (80.34\%) educated women about COVID-19, 47 (40.17\%) recommended meditation and relaxation techniques, 29 (24.79\%), sent reading material and website links, 15 $(12.82 \%)$ used distraction techniques and $2(1.71 \%)$ prescribed anti-anxiety medications.

Obstetricians ( $\mathrm{N}=117)$ mentioned the need for several resources to help them manage anxieties among mothers. Nearly $75 \%$ mentioned the need for training in simple counselling techniques, $58(49.57 \%)$ requested access to a helpline for mothers, $56(47.96 \%)$ felt videos for mothers regarding managing anxiety would be useful, 38 (32.48\%) felt easy access to mental professionals would help and $33(28.21 \%)$ requested for simple guidance notes.

\section{Discussion and conclusions}

This online survey among obstetricians from India describes the nature and frequency of concerns, anxiety and psychological distress due to COVID-19 that pregnant and postpartum women reported to them.

The lockdown has created difficulties for pregnant women to travel to hospitals and to get their scans done on time and caused concerns related to acquiring the infection at hospitals. It has also affected the financial and occupational status of couples which adds to the stress. Obstetricians reported that women contacting them about work-related concerns were a sizable number (35\%) and a quarter of them expressed feeling distressed due to missing work.

Rates of pregnancy-related anxiety even in the nonCOVID times have been high in low-income countries. Limited studies done during the current pandemic reveal anxiety rates during pregnancy in the range of 63-68\% (Corbett et al., 2020; Lebel et al., 2020; Saccone et al., 2020). It is known that pregnancy-related anxiety escalates in the third trimester and our results reflect the same. Majority of the women who contacted obstetricians for COVID-19-related anxiety in the survey were in the third trimester $82(69.5 \%)$.

Our findings reflect previous research on the role of nonjudicious use of social media amplifying anxiety further increasing the perceived risk of infection (Holmes et al., 2020). 
Table 1 Frequency of various concerns related to COVID-19 reported to obstetricians

\begin{tabular}{lll}
\hline Items $(N=118)$, concerns about & $\begin{array}{l}\text { Often or very } \\
\text { often, } N(\%)\end{array}$ & $\begin{array}{l}\text { Occasionally, } \\
N(\%)\end{array}$ \\
\hline Hospital visits for antenatal visits and scans & $85(72.65 \%)$ & $29(24.79 \%)$ \\
Methods for protection from COVID-19 & $71(60.17 \%)$ & $37(31.36 \%)$ \\
Social media messages & $61(52.14 \%)$ & $34(28.21 \%)$ \\
Safety of the infant from infection after delivery & $61(52.14 \%)$ & $38(32.48 \%)$ \\
Effect of COVID-19 on the unborn baby & $54(45.76 \%)$ & $40(33.9 \%)$ \\
Effect of COVID-19on pregnancy outcome & $53(44.92 \%)$ & $44(37.29 \%)$ \\
Safety of breast feeding & $52(44.44 \%)$ & $33(28.21 \%)$ \\
Need for caesarean section to decrease chances of COVID-19 infection & $43(34.75 \%)$ & $53(45.3 \%)$ \\
Having to be on leave from work due to restrictions & $40(34.19 \%)$ & $39(33.33 \%)$ \\
Stress related to social distancing or inability to follow social distancing & $39(33.33 \%)$ & $38(32.48 \%)$ \\
$\quad$ due to inadequate living spaces & $16(13.55 \%)$ & $64(54.24 \%)$ \\
Symptoms of COVID-19 infection & $15(12.71 \%)$ & $33(27.97 \%)$ \\
Getting tested for COVID-19 & & \\
\hline
\end{tabular}

Interestingly, there were also culture-specific concerns. In India, pregnant women usually have an important ritual called Seemantha (baby shower) in the 7th month of pregnancy for the wellbeing of the mother and unborn baby. Obstetricians reported that mothers were distressed missing out on childbirth-related rituals because of social distancing.

Studies done in Canada, Ireland and Italy among pregnant women in relation to COVID 19 have reported similar results. The Canadian study revealed high rates of depression $(37 \%)$, anxiety $(59 \%)$ and pregnancy-specific anxiety $(67 \%)$. The most prevalent COVID-19-related worries were similar to those found in our study (Lebel et al., 2020). Pregnant women in Ireland reported excessive worries regarding older relatives and unborn baby (Corbett et al., 2020) while Italian pregnant women reported high rates of anxiety regarding vertical transmission (Saccone et al., 2020).

Nearly $20 \%$ of obstetricians in our survey also reported getting calls from partners and family members with concerns and anxiety. While the obstetricians surveyed reported using several methods to handle the anxieties and distress, they also expressed the need for training and resources to handle these mental health issues.

The response rate of our survey was nearly $40 \%$ which might be an acceptable response rate for online surveys among medical practitioners especially at a difficult time like this. However, the limitations of the study include the small sample of obstetricians because of which generalisation may not be possible and a possibility of recall bias. Also, this survey was done during the lockdown and in the early stages of the pandemic. Concerns may change as the infection rates in the community become higher.

The findings of our study are important for two reasons. First, COVID-19-related anxiety during pregnancy needs to be addressed as anxiety may adversely influence pregnancy and foetal outcomes (Khalesi and Bokaie, 2018). Second, there is an urgent need to train obstetricians and midwives in managing psychological distress during the ongoing pandemic. During the SARS epidemic in Hong Kong, it was seen that midwives played a crucial role in providing care, health education and counselling to help pregnant women during and
Table 2 Frequency of anxiety and psychological distress COVID-19 reported to obstetricians

\begin{tabular}{lll}
\hline Items $(N=118)$, anxiety and psychological distress & $\begin{array}{l}\text { Often/very } \\
\text { often, } N(\%)\end{array}$ & $\begin{array}{l}\text { Occasionally, } \\
N(\%)\end{array}$ \\
\hline $\begin{array}{l}\text { Anxiety related to excessive and worrying social media messages (both } \\
\text { reading and receiving messages) }\end{array}$ & $48(40.68 \%)$ & $49(41.53 \%)$ \\
$\begin{array}{l}\text { Excessive anxiety and worry about contracting the infection } \\
\text { Distress due to boredom and feeling isolated }\end{array}$ & $47(39.83 \%)$ & $57(48.31 \%)$ \\
Feeling distressed due to missing work & $33(27.97 \%)$ & $54(45.76 \%)$ \\
$\begin{array}{l}\text { Distress due to lack of childbirth rituals (like baby showers) because of } \\
\quad \text { social distancing }\end{array}$ & $28(23.73 \%)$ & $41(34.75 \%)$ \\
Family members not following infection control procedures & $24(20.34 \%)$ & $55(47.01 \%)$ \\
Lack of sleep because of anxiety & $23(19.66 \%)$ & $54(46.15 \%)$ \\
\hline
\end{tabular}


after the crisis (Ng et al., 2004). Early identification of mental health issues in perinatal women is therefore essential for obstetric providers to liaise with mental health specialists to provide appropriate interventions.

Authors' contributions All authors contributed to the paper in accordance with guidelines.

Data availability We declare that data is transparent.

\section{Compliance with ethical standards}

Conflict of interest The authors declare that they have no conflict of interest.

Ethics approval This study was approved by the institutional ethics review committee of the National Institute of Mental Health and Neurosciences (NIMHANS).

Consent to participate Informed consent was obtained from all individual participants included in the study.

Consent for publication The participant has consented to the submission.

Code availability Not applicable.

\section{References}

Alzamora MC, Paredes T, Caceres D, Webb CM, Valdez LM, La Rosa M (2020) Severe COVID-19 during pregnancy and possible vertical transmission. Am J Perinatol 37:861-865. https://doi.org/10.1055/s0040-1710050

Brooks SK, Weston D, Greenberg N (2020) Psychological impact of infectious disease outbreaks on pregnant women: rapid evidence review. medRxiv 2020 04(16):20068031. https://doi.org/10.1101/ 2020.04.16.20068031

Corbett GA, Milne SJ, Hehir MP, Lindow SW, O'connell MP (2020) Health anxiety and behavioural changes of pregnant women during the COVID-19 pandemic. Eur J Obstet Gynecol Reprod Biol 249: 96-97. https://doi.org/10.1016/j.ejogrb.2020.04.022
Di Mascio D, Khalil A, Saccone G, Rizzo G, Buca D, Liberati M, Vecchiet J, Nappi L, Scambia G, Berghella V, D'Antonio F (2020) Outcome of Coronavirus spectrum infections (SARS, MERS, COVID 1-19) during pregnancy: a systematic review and meta-analysis. Am J Obstet Gynecol MFM 100107. https://doi.org/ 10.1016/j.ajogmf.2020.100107

Dos Santos Oliveira SJG, de Melo ES, Reinheimer DM, Gurgel RQ, Santos VS, Martins-Filho PRS (2016) Anxiety, depression, and quality of life in mothers of newborns with microcephaly and presumed congenital Zika virus infection. Arch Womens Ment Health 19:1149-1151. https://doi.org/10.1007/s00737-016-0654-0

Holmes EA, O’Connor RC, Perry VH, Tracey I, Wessely S, Arseneault L, Ballard C, Christensen H, Cohen Silver R, Everall I, Ford T, John A, Kabir T, King K, Madan I, Michie S, Przybylski AK, Shafran R, Sweeney A, Worthman CM, Yardley L, Cowan K, Cope C, Hotopf M, Bullmore E (2020) Multidisciplinary research priorities for the COVID-19 pandemic: a call for action for mental health science. Lancet Psychiatry S2215036620301681:547-560. https://doi.org/ 10.1016/S2215-0366(20)30168-1

Khalesi ZB, Bokaie M (2018) The association between pregnancyspecific anxiety and preterm birth: a cohort study. Afr Health Sci 18:569-575. https://doi.org/10.4314/ahs.v18i3.14

Lebel C, MacKinnon A, Bagshawe M, Tomfohr-Madsen L, Giesbrecht G (2020) Elevated depression and anxiety among pregnant individuals during the COVID-19 pandemic. https://doi.org/10.31234/osf.io/ gdhkt

Ng J, Sham A, Tang PL, Fung S (2004) SARS: pregnant women's fears and perceptions. Br J Midwifery 12:698-702. https://doi.org/10. 12968/bjom.2004.12.11.16710

Saccone G, Florio A, Aiello F, Venturella R, De Angelis MC, Locci M, Bifulco G, Zullo F, Di Spiezio Sardo A (2020) Psychological impact of COVID-19 in pregnant women. Am J Obstet Gynecol 223:293295. https://doi.org/10.1016/j.ajog.2020.05.003

Schwartz DA, Graham AL (2020) Potential maternal and infant outcomes from (Wuhan) coronavirus 2019-nCoV infecting pregnant women: lessons from SARS, MERS, and other human coronavirus infections. Viruses 12. https://doi.org/10.3390/v12020194

Wang, C., Pan, R., Wan, X., Tan, Y., Xu, L., Ho, C.S., Ho, R.C., 2020. Immediate psychological responses and associated factors during the initial stage of the 2019 coronavirus disease (COVID-19) epidemic among the general population in China. Int. J. Environ. Res. Public. Health 17. https://doi.org/10.3390/ijerph17051729

Publisher's note Springer Nature remains neutral with regard to jurisdictional claims in published maps and institutional affiliations. 